\title{
EDUCAÇÃO BRASILEIRA: DO ENSINO JESUÍTICO AS AULAS RÉGIAS
}

Taissa Vieira Lozano Burci

Universidade Estadual de Maringá - UEM, Faculdade de Astorga, Pedagogia, Maringá, PR. E-mail: taissalozano@gmail.com. Bolsista da Capes

\section{RESUMO}

Esse artigo pretende abordar as principais características e objetivos do ensino jesuítico e das aulas régias, bem como compreender o percurso histórico dessa mudança. O procedimento adotado é a pesquisa bibliográfica. A educação jesuítica se destacou pela formação pautada nos princípios cristãos destinada aos indígenas e as aulas régias direcionadas a elite buscaram formar indivíduos para contribuírem com o desenvolvimento político e econômico de Portugal.

Palavras-chave: Sistema Educacional, Ensino Jesuítico, Aulas Régias, Reforma Pombalina.

\section{BRAZILIAN EDUCATION: OF JESUIT TEACHING THE RULES OF SCHOOLS}

\begin{abstract}
This article aims to address the main characteristics and objectives of Jesuit education and the royal families, as well as to understand the historical course of this change. The procedure adopted is the bibliographical research. The Jesuit education was distinguished by the formation based on the Christian principles destined to the natives and the regal classes directed to the elite sought to form individuals to contribute with the political and economic development of Portugal.

Keywords: Educational System, Jesuit Education, Royal Classes, Pombaline Reform.
\end{abstract}




\section{INTRODUÇÃO}

Compreender a história educacional do Brasil é analisar o processo de formação da identidade de uma nação. É dar a devida importância a cada indivíduo que fez parte da construção e desenvolvimento deste país, entendendo os princípios e objetivos que norteavam seus trabalhos na época em que viveram.

A partir de uma pesquisa bibliográfica pretende-se analisar as principais características e objetivos do ensino jesuítico e das aulas régias que foram responsáveis pelas primeiras formas de educação no Brasil Colônia que pertencia a Portugal e seguiam as exigências estabelecidas pelo reino português.

\section{METODOLOGIA}

O procedimento metodológico utilizado foi a pesquisa bibliográfica que é realizada a partir das produções existentes dando fundamentação ao objeto de estudo. Este tipo de pesquisa permite o pesquisador encontrar diversas informações sobre a temática e selecioná-las com base no objetivo do trabalho (Gil, 2008).

\section{RESULTADOS}

A Companhia de Jesus foi uma instituição religiosa composta por jesuítas e foi fundada com o objetivo de catequizar os povos do mundo todo com base nos princípios católicos. No Brasil, reconhecido na época como Império Português, os jesuítas chegaram em 1549 sob o comando do Padre Manoel de Nóbrega. O ensino brasileiro ficou sob responsabilidade dos jesuítas durante 0 período jesuítico conforme descreve Cardoso (2004, p.179):

[...] o período compreendido entre meados do século XVI (1549) e meados do século XVIII (1759) é conhecido como período "jesuítico", uma vez que o ensino ficava ao encargo da Companhia de Jesus, instituição religiosa que ministrava um ensino básico nas "escolas de ler, escrever e contar", como eram denominadas então as escolas do ensino fundamental.

O ensino jesuítico era organizado por um código de ensino, conhecido como Ratio Studiorum ou Plano de Estudos da Companhia de Jesus. A versão final, de 1599, foi resultado das experiências da Companhia de Jesus ao longo de mais de meio século (FRANCA, 1952).

No Brasil ocorreu um árduo trabalho de catequização, os índios possuíam sua própria língua e cultura, porém era necessário adentrar as suas tribos e ensiná-los uma nova forma de vida. O Padre José de Anchieta ficou conhecido por escrever textos na língua dos indígenas e ensinar as crianças de forma que as mesmas eram responsáveis por transmitir aos pais o que aprendia. De acordo com Teixeira e Cordeiro (2008, p.4):

Diante do fato de que o fim último da vinda dos Jesuítas era a conversão dos pagãos à fé católica - ponto que eles nunca perderam de vista - observa-se que os mestres foram obrigados a ser condescendentes em vários momentos de sua obra.

Uma dessas condescendências foi o aprendizado da língua nativa; isso se deu através do contato com as crianças indígenas, pois havia grande resistência à língua invasora, sendo imprescindível a elaboração de uma "língua geral" (tupi e português mesclados).

O trabalho dos jesuítas foi responsável pelo surgimento das primeiras instituições escolares no Brasil que eram controladas pela Igreja. Como estratégia de controle e ordem os índios passivos eram enviados para os colégios para receberem formação aprofundada pautada na Ratio Studiorum. Os índios não tão passivos prestavam serviços escravos para os jesuítas. "No entanto, no 
Brasil não era possível aplicar todas as regras pelo simples fato de que não havia estudantes e professores suficientes para que fossem abertos os cursos e classes correspondentes" (COSTA; MENEZES, 2005, p.36).

O Brasil colonial estava sendo direcionado pela Igreja, por meio das dezenas de missões controladas pelos jesuítas que exploravam as terras e índios brasileiros. Porém, em 1759, depois de mais de dois séculos de ensino jesuítico o cenário educacional brasileiro sofre grandes mudanças com a expulsão dos padres dessa ordem religiosa e com a chegado de Marquês de Pombal.

O período pombalino se deu durante o reinado de D. José I que contou com o apoio de Sebastião José de Carvalho e Melo, mais conhecido como Marquês de Pombal, a esse ficou a responsabilidade de ajudar a reorganizar a estrutura política de Portugal e seus impérios.

Sebastião José de Carvalho, o Marquês de Pombal, realizou várias mudanças nos mais diversos setores da Coroa; alterações essas que afetavam diretamente o Brasil. As reformas tinham por objetivo organizar a administração, a fim de avançar nos progressos industriais da Coroa, além de adaptar sua maior colônia, o Brasil, a todos os ditames portugueses (OLIVEIRA et al, 2013, p.1).

Marquês de Pombal foi uma figura importante no campo educacional, foi o responsável pela expulsão da Companhia de Jesus de Portugal e de todos seus reinos, inclusive do Brasil. Para Pombal, os jesuítas educavam para a Igreja e do ponto de vista político isto não era interessante para Portugal, por isso promoveu várias reformas que:

[...] visavam transformar Portugal numa metrópole capitalista, seguindo o exemplo da Inglaterra, além de adaptar sua maior colônia o Brasil a fim de acomodá-la a nova ordem pretendida em Portugal. A idéia de pôr o reinado português em condições econômicas tais que lhe permitissem competir com as nações estrangeiras era talvez a mais forte razão das reformas pombalinas (SECO; AMARAL, 2006, p.2).

No Brasil os jesuítas foram os responsáveis pela criação das primeiras instituições escolares e a desenvolver a primeira forma de ensino desse local, mas centenas de anos após a chegada foram expulsos por Pombal, que acreditava que os mesmos educavam as pessoas para seguir a Igreja e isso não era interessante do ponto de vista político, pautado na nova reorganização que ele estava desenvolvendo em Portugal e em seus territórios.

Com essa atitude a Igreja perdeu seu espaço de domínio e o ensino consolidado no Brasil passou por grandes mudanças. Os colégios jesuítas existentes foram fechados e os padres proibidos de ficarem nessas terras, porém para que toda essa mudança fosse organizada foram necessárias algumas décadas para que o novo sistema de ensino se instaurasse.

Marquês de Pombal estava certo das estratégias que precisa tomar e com isso ficou conhecido por seu ódio pelos jesuítas e pelas fortes punições àqueles que se posicionavam contra os princípios do reino Português.

Durante o Reinado de D. José I e do seu primeiro-ministro, os princípios governamentais estavam repletos de aspirações de cunho econômicos e culturais. Para tanto, Pombal governava com mãos de ferro para que esses objetivos não se perdessem. Durante esse período, todo e qualquer indivíduo que se colocasse oposto aos ditames portugueses, poderia ser preso com a justificativa de ser contra o reino. $E$, é nessa vertente que encontramos o Marquês, com um dos maiores embates de sua era: a expulsão da Companhia de Jesus. 
Para ele, o afastamento dos jesuítas dessa região significava tão somente, assegurar o futuro da América Portuguesa através do povoamento estratégico. $O$ interesse de Estado acabou entrando em choque com a política protecionista dos jesuítas para com os índios e melindrando as relações com Pombal, tendo este fato entrado para a história como "uma grande rivalidade entre as idéias iluministas de Pombal e a educação de base religiosa jesuítica (SECO; AMARAL, 2006. p.05).

De acordo com Oliveira et al. (2013), Marquês de Pombal acreditava que a expulsão dos jesuítas seria a melhor forma de reconstruir o sistema de ensino brasileiro, pois ele acreditava que os jesuítas haviam atentado contra o reino, que colocavam em dúvidas a forma de domínio e o tratamento dos indígenas. Independente dos motivos de Marquês de Pombal fica claro a necessidade de resgatar o poder de Portugal em relação ao Brasil para desenvolver o poder econômico:

em relação à colônia, Pombal procurou organizar melhor a exploração das riquezas do Brasil, pois, dessa forma, aumentariam os ganhos de Portugal, tão necessários para alcançar os objetivos pombalinos referentes à economia portuguesa (SECO; AMARAL, 2006, p.3).

Marquês de Pombal conseguiu um de seus maiores e mais marcantes objetivos, expulsar os jesuítas em 1749 e foi responsável pela Reforma Pombalina instituindo uma nova forma de educação em Portugal e seus reinos.

\section{DISCUSSÃO}

Compreendendo algumas mudanças na história do Brasil, podemos analisar as principais características e objetivos dos dois primeiros métodos educacionais utilizados no Brasil.

O método educacional dos jesuítas era pautado na Ratio Studiorum que consistia em um manual para os professores, a fim de ditar as regras de organização das salas de aulas, o que ensinar, a forma de ensinar, entre outros aspectos que eram necessários para manter um padrão de ensino pautado no mesmo método e doutrina cristã. A preleção era fundamental no método jesuítico, a lição era antecipada de forma que o aluno sabia o que estudaria de acordo com seu nível intelectual (FRANCA, 1952).

As práticas pedagógicas abrangiam o desenvolvimento da memória, da ordem e da disciplina. As punições dadas pelos professores eram verbais, a fim de "apelar para os sentimentos mais nobres da honra e da dignidade" (FRANCA, 1952, p.38), porém se houvesse necessidade de castigo físico como forma de punição às faltas mais graves dos alunos era necessário chamar outra pessoa conhecido como corretor, nunca um membro da Companhia. $O$ ideal jesuítico era educar os indivíduos na doutrina cristã, pois para eles essa era uma forma de salvar os homens e glorificar a Deus (FRANCA, 1952).

O outro sistema de ensino conhecido como aulas régias é criado no Brasil pelo decreto de 28 de junho de 1759 e perdura até 1834. Segundo Cardoso (2004), é a primeira vez que o ensino passa ser responsabilidade do Estado, assim temos também um marco importante com o surgimento do ensino público brasileiro.

As aulas régias eram aulas avulsas que não estavam interligadas entre si, de forma que uma não dependia da outra. Elas vieram como um novo sistema de ensino que substituiu o ensino jesuítico. As mesmas eram coordenadas por um Diretor Geral de Estudos, mas a nomeação dos professores ficava a cargo do rei. Esse sistema de ensino segundo Cardoso (2004) era dividido em Estudos Menores e Estudos Maiores:

Os Estudos Menores eram formados pelas Aulas de ler, escrever e contar, também chamadas de primeiras letras como, aliás, ficaram mais conheci- 
das, e também pelas Aulas de humanidades, que abrangiam inicialmente as cadeiras de gramáticas latina, língua grega, língua hebraica, retórica e poética, mas foram acrescidas ao longo dos anos com outras cadeiras, como por exemplo filosofia moral e racional, introduzida a partir de 1772 (CARDOSO, 2004, 182, grifos do autor).

Os Estudos Maiores eram posteriores aos Menores e eram oferecidos nas universidades. Para Albano e Stamatto (2008, p.2), as "aulas régias buscavam dar às disciplinas uma utilidade para a vida cotidiana do homem". Considerando que na época se pensava em uma educação direcionada para a nobreza, algumas medidas foram necessárias:

[...] pôs em evidência a necessidade urgente de se promover uma cultura de base, assentada na leitura, na escrita, no cálculo elementar, sem esquecer os conhecimentos relacionados às obrigações religiosas e civis, além de que, para aqueles funcionários que ocupassem posições de maior destaque dentro da estrutura administrativa, era conveniente uma qualificação literária maior do que a necessária à média do funcionalismo (CARDOSO, 2004, p.181).

Em 1772, foi criado o subsídio literário que era encaminhado ao rei, era um imposto sobre a carne, vinho, vinagre e aguardente como uma forma de manutenção das aulas régias. Mas mesmo com esse imposto os professores demoravam a receber e precisavam se manter por conta própria. O subsídio literário não era suficiente para manter as aulas régias pelo Brasil que era direcionada apenas a elite e de acordo com Vaz (2010, p.8) era desviado:

Contudo, a reforma Pombalina era ineficiente em relação a algumas lacunas encontradas no sistema educacional brasileiro, que, embora tivesse mais de dois séculos datado o seu início, ainda era incipiente e continuava com a marca do elitismo: uma educação para poucos. E, não bastassem tais situações adversas, ainda contava com o desvio do subsídio literário, o qual deveria arcar com os custos da educação na colônia, para Portugal.

Observarmos que o subsídio literário não resolveu o problema do sistema educacional brasileiro, porém de acordo com Oliveira e Ramalho (2002, p. 5) a criação desse imposto foi errônea, pois sempre se mostrou insuficiente para cobrir as despesas existentes.

O sistema educacional brasileiro sofreu com as reformas pombalinas e não atingiu os objetivos esperados por falta de manutenção do ensino. Na acepção de Mello (2013, p. 5):

embora as Reformas Pombalinas determinassem a criação de escolas de primeiras letras nos domínios do além mar português, o desenvolvimento das aulas régias deu-se em ritmo lento, pela falta de recursos e a resistência as reformas. [...] A partir de 1772 a Real Mesa Censória passou a controlar o sistema escolar em Portugal e domínios d'além mar, fiscalizando concursos, freqüência e exercício docente.

Infelizmente a Reforma Pombalina não foi suficiente para determinar um sistema de ensino público brasileiro forte e a situação educacional brasileira sofreu novas mudanças com a chegada da família real ao Brasil.

\section{CONCLUSÃO}

A educação no Brasil teve seu início com a educação jesuítica, pautada na Ratio Studiorum. Essa foi a primeira forma de educação dos povos que habitavam o território brasileiro que perten- 
cia ao reino de Portugal. Os jesuítas foram responsáveis pela educação e reorganização cultural dos povos indígenas que aprenderam forçadamente novas práticas e normas sociais distintas das que eles seguiam e acreditavam.

Os jesuítas foram importantes para o desenvolvimento inicial do Brasil, mas um pouco mais de dois séculos de permanência no Brasil foram expulsos de todos os reinos de Portugal, uma vez que não atendiam mais as necessidades econômicas e políticas que estão sendo instauradas, tendo por característica principal uma nova reforma de reorganização desses setores sociais. Marquês de Pombal foi o responsável pela expulsão dos jesuítas e implementação da nova reforma educacional que ficou conhecida como aulas régias.

Foi com estas aulas que surgiu no Brasil o primeiro sistema de ensino público. Mas na realidade a educação popular foi abandonada. As aulas régias eram aulas isoladas e destinadas a elite, era uma forma de educar com todos os princípios necessários aqueles que futuramente poderiam preencher cargos importantes nos mais diversos setores responsáveis pelo fortalecimento de Portugal.

Marquês de Pombal foi importante para a nova reorganização de Portugal, criou um sistema de ensino, modificou as práticas pedagógicas existentes, mas no decorrer dos anos o sistema educacional brasileiro não foi organizado, ficando em estado precário. Novas mudanças educacionais no Brasil foram possíveis a partir de 1808 com a chegada da família real.

\section{REFERÊNCIAS}

ALBANO, Paula Lorena Cavalcante; STAMATTO, Maria Inês S. A história ensinada e as aulas régias na capitania do Rio Grande (1808 - 1821). Mneme - Revista de Humanidades. UFRN. Caicó (RN), v. 9. $\mathrm{n}$. 24, Set/out. 2008.2 Disponível em: <http://www.cerescaico.ufrn.br/mneme/anais/st_trab_pdf/pdf_st1/paula_albano_st1.pdf.>. Acesso em 09 jul. 2015.

CARDOSO, Tereza Fachada Levy. As aulas régias no Brasil. In: STEPHONOU, Maria; BASTOS, Maria Helena Câmara. Histórias e memórias da educação no Brasil: Vol. I. Séculos XVI - XVIII, 2004, p.179-191

COSTA, Célio Juvenal; MENEZES, Sezinando Luiz. A educação no Brasil colonial (1549-1759). In: Fundamentos históricos da educação no Brasil. Maringá: EDUEM, 2005, p. 29-43

FRANCA, Leonel. O método pedagógico dos jesuítas - O "Ratio Studiorum" Introdução e Tradução. Rio de Janeiro: Livraria Agir Editora, 1952. Disponível em: http://www.histedbr.fae.unicamp.br/acer_fontes/acer_histedu/brcol012.htm. Acesso em: 06 mar. 2015.

Gil, Antonio Carlos. Métodos e técnicas de pesquisa social. 6. ed. São Paulo: Atlas, 2008.

MELLO, Saulo Álvaro de. Aulas régias na gênese da instrução pública na Capitania de Mato Grosso. 2013.

Disponível

em: <http://www.histedbr.fae.unicamp.br/acer_histedbr/jornada/jornada11/artigos/4/artigo_simposi o_4_907_sauloamello@hotmail.com.pdf<. Acesso em: 09 jul. 2015

OLIVEIRA, José Pedro Garcia; RAMALHO, Betânia Leite. As aulas régias na capitania do Grão-Pará (1759-1808). $2002 . \quad$ Disponível em: <http://sbhe.org.br/novo/congressos/cbhe2/pdfs/Tema7/7106.pdf>. Acesso em: 09 jul. 2015 
OLIVEIRA, Natália Cristina de; BORGES, Felipe Augusto Fernandes; BORTOLOSSI, Cíntia Maria Bogo; MARQUES, Daniella Domingues Alvarenga; COSTA, Célio Juvenal. Marques de Pombal e a expulsão dos jesuítas: Uma leitura do iluminismo português no século XVIII. 2013. Disponível em: < http://www.histedbr.fae.unicamp.br/acer_histedbr/jornada/jornada11/artigos/4/artigo_simposio _4_805_nat_oliveir@hotmail.com.pdf>. Acesso em: 30 jun. 2015

SECO, A. P. e AMARAL, T. C. I. do. Marquês de Pombal e a reforma educacional brasileira. 2006.

Disponível

em:

<http://www.histedbr.fae.unicamp.br/navegando/periodo_pombalino_intro.html>. Acesso em: 02 jul. 2015.

TEIXEIRA, Olga Sueli; CORDEIRO, Rubério de Queiroz. Educação jesuíta: objetivo, metodologia e conteúdo nos aldeamentos indígenas do Brasil colônia. Anais do II Encontro Internacional de História Colonial. Mneme - Revista de Humanidades. UFRN. Caicó (RN), v. 9. n. 24, Set/out. 2008. Disponível

em:

<http://cerescaico.ufrn.br/mneme/anais/st_trab_pdf/pdf_st1/olga_teixeira_st1.pdf >. Acesso em: 05 jul. 2015

VAZ, Fabiana Andréa Barbosa. História da educação e da escola brasileira: Uma peça "encenada" em um "cenário" político - econômico nacional? 2010. Disponível em: <https://www.google.com.br/url?sa=t\&rct=j\&q=\&esrc=s\&source=web\&cd=1\&ved=0CB4QFjAA\&ur I=http\%3A\%2F\%2Fwww.histedbr.fae.unicamp.br\%2Facer_histedbr\%2Fjornada\%2Fjornada9\%2F_fi les\%2FJfqqpDnO.doc\&ei=JaK9U6iaJsnTsASB24CwCw\&usg=AFQjCNEwBdyXQqqH0_X2ZtiNlaSAr563Q\&sig2=k8dGN_2I_QNDuSAbCWaTfw>. Acesso em 09 jul. 2015 